\title{
DAMNATIO MEMORIAE
}

\section{DAMNATIO MEMORIAE}

José Antonio Martínez Pons: Departamento de Química Analítica e Ingeniería Química. Universidad de Alcalá de Henares. Madrid (España) joseantonio.martines@uah.es

\section{CURRÍCULUM VITAE}

Licenciado en Ciencias Físicas (Geofísica) por la Universidad Complutense de Madrid (España) y en Ciencias Químicas (Química física) por la UNED (España). Doctor por la Universidad de Alcalá de Henares (España) en el año 2000. Profesor de la Universidad de Alcalá de Henares en el área de Química analítica e Ingeniería química.

\section{RESUMEN}

Damnatio Memoriae es una locución latina que significa literalmente condena de la memoria. Era una práctica de la antigua Roma consistente en, como su propio nombre indica, condenar el recuerdo de un enemigo del Estado tras su muerte. Se aplicaba para eliminar del mapa a algún personaje incómodo y todo cuanto recordara al condenado: imágenes, monumentos, inscripciones, e incluso se llegaba a la prohibición de usar su nombre. Muchos emperadores también se vieron afectados por esta práctica. Algo así ha ocurrido en España con la época franquista. 


\title{
PALABRAS CLAVE
}

Damnatio Memoriae - España - Franquismo

\begin{abstract}
Damnatio Memoriae is a Latin phrase that literally means conviction of memory. It was a practice of ancient Rome consisting of, as its name suggests, to condemn the memory of an enemy of the state after his death. Applied to remove a character map to uncomfortable and reminded all that the condemned images, monuments, inscriptions, and even came to the ban on his name. Many emperors were also affected by this practice. Something has happened in Spain with the Franco era.
\end{abstract}

\section{KEY WORDS}

Damnatio Memoriae - Spain - Franco

\section{TEXTO:}

Advertencia para evitar malos entendidos: Quien esto suscribe nunca tuvo nada que ver con el "Régimen anterior", ni siquiera asistió a los campamentos del Frente de Juventudes con los que se aprobaba la FEN (supongo que ahora se harán talleres de técnicas afectivo-sexuales, con prácticas incluidas, para aprobar la Educación para la ciudadanía) y no fue ni más ni menos franquista que la mayoría de sus coetáneos, en cualquier, caso siempre por omisión. 
Recuerdo que cuando era yo un mocoso de una docena de años, estudiante de segundo o tercero de bachillerato (no mero asistente a clase) tenía entre otros excelentes profesores a Don Bernardo Villalonga, profesor de Historia. Era un profesor en aquel entonces, algo atípico, ya que no nos exigía fechas ni listas de reyes. Lo siento por los psicopedagogos modernos, pero a mi nadie me obligó a aprenderme la lista de los reyes Godos, ni conozco a nadie a quien se la hayan hecho aprender, aunque como profesor pienso que efectivamente aprenderse la lista de los reyes godos o la tabla periódica o los valores de las constantes universales con siete decimales es una estupidez, pero el ejercicio mental de hacerlo no lo es en absoluto. Díganme por ejemplo, ¿hay algo más estúpido que pasar un balón por un aro, meterlo entre tres palos o correr como un loco dando vueltas a un estadio, es decir, para no ir a ninguna parte? Son estupideces por las cuales algún cretino ha sufrido un infarto de miocardio o algún descerebrado ha llegado a matar, y que permiten a algunos de quienes las practican vivir con unos ingresos miles de veces mayores que la media de sus conciudadanos.

A lo que iba, un día le pregunté al Sr. Villalonga por qué las guerras las ganaban siempre "los buenos".

- $i$ Pero es que no se ha dado usted cuenta (entonces la mayoría de profesores a los estudiantes de bachillerato nos trataban de usted, y esto a mi juicio era bastante mejor que la cutrez actual) de la que historia la escriben los vencedores?

Me lo creí y, conforme fui creciendo, vi que en efecto era así, pero, como se verá más adelante, había excepciones.

En todas las guerras se cometen barbaridades, la propia guerra es una barbaridad. Las barbaridades que comete el "enemigo" son imperdonables, son salvajadas, mas si 
estas mismas, o mayores, las cometen los vencedores son actos heroicos o al menos necesarios.

El mundo olvida el arrasamiento de Dresde, Colonia o Hamburgo con centenares de miles de muertos pero los bombardeos de Londres fueron una salvajada y los de Paris y otras ciudades de la Francia ocupada, una necesidad estratégica. Incluso se ignora que, en la Segunda Guerra Mundial, el primer bombardeo sobre objetivos civiles lo llevó a acabo... la RAF. Sólo se escandaliza la gente por los bombardeos de Hiroshima y Nagasaki y eso por cierta propaganda de post guerra que hizo de EE.UU., el enemigo malísimo.

A veces, la mejor solución es no hablar mucho de unos y nada de otros, valga el caso de los seis millones del holocausto frente a los ignorados millones de muertos en los Gulag, la revolución cultural o en la Camboya de Pot Pol.

Otra de las tendencias del ser humano vencedor, sobre todo si el vencido es de casa, es borrar toda memoria de éste.

Así por ejemplo, en el antiguo Egipto, se quiso eliminar todo recuerdo del faraón hereje Akenatón, borrando hasta los cartuchos en que se le nombraba o de la reina faraona Hapsetsup (o como se escriba). En estos casos no se consiguió, aunque tal vez se consiguiera con otros personajes de los que no tenemos, por el momento, ni idea de su existencia.

En Roma se aplicaba la Damnatio memoriae, para eliminar del mapa algún personaje incómodo. Incluso en la gruta de Belén plantaron un bosque dedicado al dios Adonis para eliminar todo recuerdo de Jesucristo. 
Algunas veces los huecos se recubren con reescrituras de la historia, hacer desaparecer unos días del calendario es relativamente fácil, valga la reforma gregoriana, (aunque esta reforma es responsable de que Newton naciera o no el mismo año de la muerte de Galileo), pero hacer desaparecer décadas, aun en tiempos en que la historia no se documentaba como ahora, es asaz complejo. La solución pues es borrar el pasado y escribir encima, como los viejos programas de destrucción de archivos informáticos (¿No les recuerda la trama de "1984" de George Orwell?)

Normalmente estos sucesos ocurren nada más desaparecido el personaje incómodo, sólo en casos excepcionales tienen lugar "con efecto retroactivo". Todos recordamos la artillería talib machacando los Budas de Afganistán. Tomen nota y ejemplo quienes proponen dinamitar el Valle de los Caídos.

Pero volvamos a España. Perdón, al estado ibérico complementario de Portugal.

Como siempre Spain is different.

En España la historia reciente y de rebote la más antigua, en cuanto pueda tener influencia en la reciente, no la han escrito los vencedores, ni siquiera los vencidos, en muchos casos la han escrito hijos o nietos de los vencedores que piensan que sus padres o abuelos debían estar en el bando vencido y desean hacérselo perdonar, con la furia de conversos. (También ciertos "hispanistas" extranjeros que muy buenos dividendos están sacando y a los que incluso, una vez más nuestro papanatismo congénito, se les hace más caso que a los compatriotas, aunque no digan más que sandeces).

Deberían hacerse perdonar también su absoluta ineficacia en los 40 años de Dictadura. 
La primera damnatio memoriae aplicada al régimen anterior (que también la había practicado con algunos símbolos republicanos) no pasó de cambiar los nombres de algunas calles, disimuladas con el cambio a nombres tradicionales. Yo nací en un placita que llamaban del Rastrillo, con el cambio le pusieron de la Pescatería y de paso cambiaron la calle del general Godet y alguna más, menos mal que dejaron la del Alférez Gralla Lladó o del Flecha Matas Serra (posiblemente temibles fascistas).

Han pasado treinta años de la muerte, natural y en la cama de Franco, un poco menos desde el suicidio ritual de las cortes franquistas.

En estos treinta años, los que en su momento no decían esta boca es mía ni en las tertulias de café, incluso algunos chuparon del bote con la "ominosa", se han ido labrando un pasado ideal e ideológico. Los intelectuales de izquierdas (¿se puede ser intelectual y no ser de izquierdas?) sobre todo los intelectuales de izquierdas que viven de derechísma, la mayoría , como dije antes, verdaderos "hijos de papá", han creado una historia, recuperación de la memoria histórica la llaman, en donde no sólo se han exagerado y si es preciso, inventado, las infamias cometidas "por Franco", sino que se han negado, ocultado o elevado a la categoría actos heroicos, las infamias cometidas en nombre de la "libertad", la "República" o la "legalidad vigente", desde los "paseos", las "checas", "las brigadas del amanecer", hasta los bandoleros a quienes se dio una razón, en apariencia noble, para que desataran sus más bajos instintos, no mencionando siquiera que muchas de las represalias nacionales fueron consecuencia de la ferocidad republicana, que asesinó, por ejemplo, a casi 8000 religiosos (ya algunos iluminados quieren que la Iglesia "pida perdón") y prácticamente exterminó a toda la oficialidad del Cuerpo General de la Armada que cayó en sus manos, valga el buque Plus Ultra de luctuoso paradigma, claro que en el pecado llevaron penitencia, la inefectividad de la Flota Republicana fue clara y notoria. Para conducir un barco de guerra no basta la intuición y la experiencia de pistolero sindical. Hasta los últimos fusilados por el régimen de Franco, vulgares asesinos, se han presentado 
como campeones de la libertad. (No soy más generoso juzgando los guerrilleros de la guerra de la independencia, como no lo fue Goya y ¡lo que le costó!, salvas siempre las distancias).

La ignorancia querida o involuntaria es manifiesta.

No voy a seguir por ahí, pero mi afición, el modelismo militar, me ha llevado a averiguar muchas cosas, -como el tópico de la inferioridad en armamento de la República, sólo aceptable en algunos momentos y en algunas parcelas,- que sólo mencionarlas significa entrar en el gremio de los fascistas, como lo significa no estar de acuerdo con las historias tópicas, incluso o peor cuando se aportan documentos incontestables. En este caso, al no haber posibilidad de réplica científica se recurre al insulto y vuelta al tópico.

Sólo así se explica lo que ahora está pasando. En 1975 muchas gentes en pleno uso de facultades mentales recordaban lo que en realidad había ocurrido, mentir y exagerar no era tan fácil. Hoy ya no quedan muchos y ha habido tiempo de llenar a la población de mensajes subliminales.

Lo más grave es que en este afán de reescribir la historia pro domo suo, se han resucitado viejos fantasmas que ya parecían afortunadamente enterrados y se están levantado de nuevo odios entre españoles. Una vez más el instinto cainita de ser humano exacerbado en "culturas calientes" como la nuestra. El desmoronamiento de la antigua Yugoslavia puede servir de modelo a no imitar.

Ya puede entronizarse la "verdadera historia" que nunca ocurrió y culminar, dinamitando estatuas como los talib de Afganistán y también homenajeando a criminales, aunque sean fósiles vivientes. ¿Era esto necesario? Muchas cosas las comprendo al ver como se está dando al sindicato afín al Gobierno lo que se le está 
dando, con base en unos presuntos derechos, ni mucho menos demostrados, y en cualquier caso ya pagados. ¿No entraron los sindicatos de clase a saco en el antiguo patrimonio de la Organización Sindical franquista? ¿No han estado subsistiendo los actuales sindicatos por todo lo alto a costa del bolsillo de todos los españoles, sindicalistas o no? ¿Todavía quieren más? ¿Dónde están los bienes de los sindicatos católicos o de la CNT? Píenselo quienes exageran las ayudas a la Iglesia Católica, también desposeída de sus bienes en algunos momentos de la historia, y cuenten el número de afiliados, incluso de votantes a los sindicatos y comparen con el número de quienes se confiesan "afiliados" a la Iglesia, cumplan o no, eso sin mencionar la ingente cantidad de obras sociales que la Iglesia sostiene, bastantes más que todos los sindicatos juntos y por mucho menos dinero... También se ha hecho damnatio memoriae con el caso PSV, esta vez por otras razones, como se hará simplemente "desmemoriatio" de la condonación de los créditos a eminentes defensores del progreso. Quizás convenga eliminar los registros universitarios, para que personajes públicos, sin siquiera el bachillerato, se atribuyan títulos superiores

En resumen pienso que se trata de aplicar con efecto retroactivo aquello de "a moro muerto gran lanzada", con un objetivo, borrar en el territorio ibérico complementario de Portugal todo recuerdo de algo que no sea "izquierda", aunque ello signifique destruir lo que costó muchos siglos y mucha sangre sudor y lágrimas edificar. 